\title{
IV \\ CONCEITUALIZAÇÕES DE TERRITÓRIO AMAZÔNICO E UM RETRATO HISTÓRICO DAS QUESTÕES AGRÁRIAS NO BRASIL*
}

\author{
Julliany Xavier de Sousa ${ }^{1}$ \\ Simone Kelly Rabelo Martins ${ }^{2}$
}

\section{Introdução}

A Amazônia destacou-se no âmbito mundial atraindo atenção por meio da sua biodiversidade, no entanto, para este artigo o foco central está na Amazônia a partir da diversidade conceitual acerca do que é território, tendo em vista a particularidade cultural dos povos que nela habitam, além das questões ambientais. Objetiva retratar as diversas concepções de território que constituem este mosaico de terra dentro do espaço Amazônico e os diferentes conceitos atribuídos a ele, assim como conhecer um pouco mais acerca dos povos da Amazônia e como funciona a sua relação com a natureza e os conflitos ambientais existentes.

O texto também traz uma abordagem acerca da disputa de terras no Brasil, dos movimentos sociais em defesa do direito a terra e das questões agrárias e fundiárias, além do agronegócio que foi expandindo suas fronteiras agrícolas por todo o país chegando até a áreas ambientais mais importantes como as que existem na Amazônia.

\section{Território e seus pressupostos conceitos}

A concepção mais comum de território vem da ciência geográfica destacando que existem várias correntes de pensamento e concepções *DOI - 10.29388/978-65-86678-45-1-0-f.91-102

${ }^{1}$ Pedagoga pela UFPA, Especialista em Coordenação Pedagógica pela UFOPA e Mestranda em Educação pela UFOPA. E-mail: juliany30@hotmail.com

${ }^{2}$ Pedagoga pela ULBRA, Especialista e Psicologia Educacional com ênfase em Psicopedagogia Preventiva pela UEPA e Mestranda em Educação pela UFOPA. E-mail: simonekellynda@gmail.com 
acerca do conceito "território", sendo que este é classificado como uma categoria, onde encontram-se também a paisagem, lugar, região e espaço e todos estes componentes constituem uma das principais bases de estudo da Geografia. No entanto, faz-se necessário destacar que "território" não é um conceito exclusivamente da Geografia, sendo que o termo também é utilizado pelas ciências sociais, humanas e da saúde o que o torna polissêmico e não generaliza o seu conceito somente as questões ligadas a ciência geográfica.

A partir da concepção da ciência geográfica moderna podemos afirmar que o território passou a ser concebido como o solo (terra) e o povo (habitantes) sendo estes os pilares sobre o qual se constrói e está organizada a sociedade atual chamada de Estado Moderno por Ratzel ${ }^{3}$ (1990 [1914]),

Não é possível conceber um Estado sem território e sem fronteiras [...] assim também a sociedade mais simples só pode ser concebida junto com o território que lhe pertence. $\mathrm{O}$ fato de estes dois organismos estarem ligados ao seu solo é a consequência natural da ligação evidente que une a criatura humana à Terra (RATZEL, 1990, p. 73).

Dito isto, é importante compreender que o termo território não se limita apenas a ideia de espaço de terra e suas fronteiras, porém, caracteriza-se pela ideia de posse, domínio e poder por parte dos povos que nele habitam.

A partir dessa concepção de território como Estado Moderno, o geógrafo Milton Santos ${ }^{4}$ apresentou críticas baseadas no pensamento marxista contra o sistema capitalista diante da relação dos conceitos teóricos predominantes na ciência geográfica ou nova geografia que é marcada pela presença do neopositivismo, tendo como base as técnicas estatísticas (quantificação).

\footnotetext{
${ }^{3}$ Friedrich Ratzel foi responsável por elaborar o conceito de território na Geografia Moderna o chamado Estado Moderno.

${ }^{4}$ Milton Santos foi um geógrafo brasileiro, considerado por muitos como o maior pensador da história da Geografia no Brasil e um dos maiores do mundo. Destacou-se por escrever e abordar sobre inúmeros temas, como a epistemologia da Geografia, a globalização, o espaço urbano, en tre outros.
} 
Em sua obra o geógrafo "Geografia Nova", defendia principalmente o conceito de "território" como o caráter social do espaço através da noção de "meio técnico-científico informacional", que seria a transformação do espaço natural realizada pelo homem através do uso das técnicas.

\section{O Pluralismo Cultural em Território Amazônico}

O território Amazônico constitui-se como um mosaico de espaços onde a população estabelece uma relação de produção e dependência com a natureza, sendo que para muitos povos que habitam a Amazônia brasileira principalmente os indígenas a terra possui um sentido sagrado e um grande valor existencial, ou seja, o território vai para além de um conceito espacialmente geográfico.

Explorar os recursos naturais (água, terra, minerais, flora e fauna) faz parte da cultura dos povos da Amazônia. Tal cultura faz parte da sobrevivência física de muitas populações que compartilham dessa forma coletiva de produção e subsistência e é dessa forma que pequenos produtores e agricultores vão resistindo aos avanços do agronegócio na região Amazônica.

Amazônia é dotada de uma cultura própria e bastante peculiar e este Pluralismo Cultural ${ }^{5}$ tem raízes profundas nos povos indígenas que foram os primeiros habitantes deste território. Todavia, assim como em outros espaços do Brasil Colonial a vinda dos europeus e africanos resultou na evolução cultural e étnico-racial dos povos da Amazônia. Sobre isso, Colares (2011, p.3), destacam,

[...] ressalta-se que: ...a composição humana amazônica é dinâmica, múltipla, e em vários aspectos, singular, e ainda pouco conhecida, especialmente se considerarmos a amplitude do território e as grandes irregularidades na presença humana. Há estudos significativos neste particular, em diversas áreas do conhecimento, mas não raro nos deparamos com análises nas quais a parte é tomada

\footnotetext{
${ }^{5}$ Pluralismo cultural é um termo usado quando grupos menores dentro de uma maior sociedade manter suas únicas identidades culturais e seus valores e práticas são aceitas pela cultura mais ampla desde que sejam consistentes com as leis e os valores da sociedade em geral.
} 
pelo todo, e a caracterização populacional de um "pedaço" da Amazônia é utilizada como expressão representativa da região como um todo.

$\mathrm{Na}$ maioria das vezes o território Amazônico é notado somente por sua grande biodiversidade (florestas, rios, fauna, flora, minerais e etc), no entanto, não podemos deixar de notar sua principal riqueza a sociodiversidade ${ }^{6}$ que é marcada por modelos diversificados de cultura, valores, etnias e crenças sendo estes os componentes necessários para condição existencial dos povos da Amazônia quanto a isso, segundo Costa e Brasileiro (2016, p. 71) alertam que,

Se antes a Amazônia se via, mas não via o mundo, devido aos seus apagões estruturais, hoje a Amazônia consegue ver muito do mundo, mas a opacidade do capitalismo não nos deixa enxergar nossas próprias raízes, nossas diversidades culturais e sociais.

Ante ao exposto, a cultural amazônica possui traços peculiares decorrentes da diversidade de povos (indígenas, quilombolas, ribeirinhos, camponeses, da floresta e urbanos) existentes neste local. Para Loureiro (2001), o capitalismo ainda não se apoderou totalmente nesse espaço da Amazônia, diante dessa resistência a influência de cada povo e sua etnia enriquece e dá uma originalidade particular a cultura tradicional desta região.

\section{A relação do homem com a natureza e conflitos ambien- tais na Amazônia}

Desde os primórdios o homem sempre estabeleceu uma relação profunda com a natureza, tirando dela por meio do trabalho os meios necessários para a sua condição existencial e qualidade de vida. Na Amazônia não foi diferente ao longo dos anos os povos que nela habitam exploraram de forma utilitária os seus diversos recursos naturais (água, ter-

\footnotetext{
${ }^{6}$ Sociodiversidade é a posse de recursos sociais próprios, de modelos diferentes de autoridade política, de acesso à terra ou de padrão habitacional, de hierarquias próprias de valores ou prestígio. É a diversificação de culturas, etnias, raças e ideologias presentes na sociedade.
} 
ra, florestas, minerais e etc) de modo a atender suas necessidades mais básicas como alimentação por meio da agricultura familiar.

Um exemplo desse tipo de relação são dos povos ribeirinhos que residem no entorno dos rios da Amazônia, pois os mesmos vivem da cultura pesqueira artesanal sendo que na maioria das vezes a pesca é somente para o consumo familiar ou comunitário das pessoas que fazem parte daquela região.

Devido aos avanços do agronegócio que tem por finalidade integrar a Amazônia a economia não só nacional como mundial as formas de exploração da natureza e as relações do homem com a mesma mudaram nos últimos 30 anos. Com isso, sugiram as diversas formas de exploração dos recursos naturais como: terra para pastagens, fontes de água, floresta para a retirada de madeira, exploração de plantas para uso medicinal e cosmético, venda de animais silvestres e a corrida pela exploração dos minérios.

Diante do avanço crescente das grandes fronts agropecuários os pequenos produtores e agricultores que em sua maioria são posseiros tem suas terras invadidas ou compradas devido a expansão das fronteiras agrícolas o que resulta em outra problemática que é a saída dos povos de sua terra para as áreas urbanas devido as questões agrárias existentes.

\section{A Questão Agrária no Brasil: Um breve contexto Históri- co}

A questão agrária no Brasil se constitui com um problema estrutural desafiando estudiosos e pesquisadores, entre as problemáticas discutidas a amplitude das várias disputas entre elas a disputa de terra que envolvem grandes latifúndios, grilagem, exploração do trabalho, degradação ambiental entre outros problemas relacionados a concentração fundiária. Uma problemática que remonta à colonização brasileira.

Geralmente ao falar em questões agrarias, imediatamente nos remetemos ao termo reforma agraria, que apesar de estar dentro da mesma problemática são termos que se diferem, pois, entende- se que a Reforma Agraria trata- se de uma política pública resultante das lutas e conquista 
de uma população que vive na zona rural mas não tem acesso à propriedade de terra enquanto as questões agrarias de acordo com Fernandes (2008) é "um problema estrutural do capitalismo" causando conflitos, exclusão, desigualdades sociais, expropriação e, portanto, necessita de uma política territorial: A reforma agrária.

Pode- se dizer que o monopólio de terras no Brasil tem suas origens no século XVI com as Capitanias Hereditárias ${ }^{7}$ doadas pelo Rei Dom João III aos nobres de sua confiança quando o Brasil foi divido em 15 lotes de extensões de terra tornando-se propriedades de fidalgos. A estrutura fundiária Brasileira origina- se daí com os grandes latifúndios escravistas resultante da má distribuição de terras iniciadas na colonização permanecendo até os dias atuais apenas com novas roupagens.

Mais de 500 anos depois da colonização ainda vemos os resultados desse modelo embora o discurso de que a diminuição dessa desigualdade tenha diminuído elas permanecem e os latifúndios no Brasil predominam e os que permanecem no campo vivem em situações difíceis como pequenos investimentos diante das necessidades do agricultor.

A base do latifúndio brasileiro é composto por trabalho escravo de início de origem indígena e posteriormente de negros vindo das aldeias africanas principalmente nas lavoras de açúcar no nordeste brasileiro que teve seu auge no século XVI e XVII. As sesmarias ocasionou as grandes formações dos latifúndios brasileiros.

Com a pressão dos ingleses para a abolição da escravidão e substituição por trabalho assalariado, em 1850 foi criada a Lei de Terras no Brasil baseada na relação de igualdade e liberdade defendida na Revolução Francesa ${ }^{8}$ assimilado pelo capitalismo nascente onde neste discurso os trabalhadores devem ser livres para venderem sua força de trabalho aquém puder pagar o que não ocorria quando o escravo era propriedade, portanto, sem direito de vender sua força de trabalho. (MARTINS, 1995, p. 153). Só que o escravo se tornaria livre para vender sua força de traba-

\footnotetext{
${ }^{7}$ As capitanias do Brasil foram uma forma de administração territorial da América portuguesa, parte do Império Português, pela qual a Coroa, com recursos limitados, delegou a tarefa de colonização e exploração de determinadas áreas.

${ }^{8}$ Revolução Francesa foi um período de intensa agitação política e social na França, que teve um impacto duradouro na história do país e, mais amplamente, em todo o continente europeu. A monarquia absolutista que tinha governado a nação durante séculos entrou em colapso em apenas três anos
} 
lho e não para tornar- se dono de suas próprias terras. É nesse sentido que a Lei de Terras no Brasil foi criada.

A Lei de Terras instituía que "qualquer cidadão brasileiro poderia se transformar em proprietário privado de terras", desde que pagasse o valor certo a coroa. Qual seria esse valor certo? Pode- se observar desde ai o impedimento do acesso à terra embora a lei afirmasse que qualquer cidadão teria direito a terra, na prática, como nos dias atuais somente aqueles com poder aquisitivo pode ter acesso à terra.

A Lei ${ }^{\circ}$ 601, de 1850, foi então o batistério do latifúndio no Brasil. Ela regulamentou e consolidou o modelo da grande propriedade rural, que é a base legal, até os dias atuais, para a estrutura injusta da propriedade de terras no Brasil. (STEDILE, 2012, p. 25).

De 1850 a 1930 se dá a consolidação do latifúndio agrário no Brasil com o impulso da industrialização por Getúlio Vargas e promessas de bons salários, saúde e educação que levaram muitas pessoas do campo para o centros urbanos onde a realidade foi outra, com mão de obra barata foram morar nas periferias e favelas e sem condição de voltar para suas origens. O Brasil durante séculos foi um país agrário, todavia, "O campo brasileiro moderno repele os pobres e os trabalhadores da agricultura capitalizada vivem cada vez mais nos espaços urbanos" (SANTOS, 2009, p. 10).

Entre os séculos XVI e meados do XX a economia brasileira pautou- se na produção de café e açúcar, sendo, por conta desse fato considerado um país rural uma vez que grande parte da população vivia no campo e do campo. Com a crise de 1929 e a queda do principal produto de exportação brasileiro, os grandes latifundiários precisaram encontrar outra forma de se reerguer e consequentemente reerguer a economia com apoio estatal passando assim a investirem na industrialização intensificada em 1956 com a política de Juscelino Kubitschek e sua política desenvolvimentista.

A produção capitalista no Brasil ocorreu principalmente por essa fusão da indústria e os proprietários de terra: 
Mas, foi na segunda metade do século XX que esta fusão se ampliou significativamente. Após a deposição, pelo Golpe Militar de 64, de João Goulart, os militares procuraram ressoldar esta aliança política, particularmente porque durante o curto governo João Goulart ocorreram cisões nas votações do Congresso Nacional em aspectos relativos à questão agrária, principalmente quando uma parte dos congressistas votaram a legislação sobre a Reforma Agrária (OLIVEIRA, 2001, p. 186).

Após esse momento entra o período militar com planos de desenvolvimento pautado na manutenção de padrões dominantes de acumulação com intuito de modernizar a agricultura aumentando a produtividade, para isso facilitou a exportação, aumentou os créditos agrícolas incentivando a pesquisa e técnicas modernas de produção.

Entre as décadas de 1960 e 1980 devido a inversão de técnicas desenvolvidas na agricultura o período foi marcado como "a revolução verde”, fator que reforça o que já dito acima quanto ao monopólio de terra e favorecimento aos grandes latifundiários.

No século XX dentre as transformações ocorridas no espaço agrário brasileiro surge a reforma agrária como uma política pública que resolveria o problema fundiário no Brasil ganhou forças em 1950 com os movimentos das chamadas ligas camponesas que foram uma organização política dos camponeses que resistiam a expulsão e expropriação de terras.

As lutas se intensificaram no século XX juntamente com os conflitos agrários com trabalhadores resistindo e lutando por um pedaço de chão e a formação do MST (Movimentos dos Trabalhadores Sem Terra) em 1979, período em o MASTER (Movimento dos agricultores sem terra) nascidos uns anos antes, faziam a ocupação de acampamentos embora oficialmente o MST tenha surgido em 1984 no $1^{\circ}$ Encontro dos Trabalhadores Rurais Sem Terra, em Cascavel-PR se tornando ao longo de sua caminhada um espaço político. Com a redemocratização brasileira em 1985 foi criado o primeiro Plano Nacional para a Reforma Agraria fortemente combatido pelos ruralistas. 
Com a Constituição Federal de 1988 o estatuto da propriedade fundiária legitimou a função social da terra embora os ruralistas tenham tido ao seu favor emendas constitucionais, os movimentos sociais também tiveram importantes conquistas ao que se refere ao direito das terras em seu art. 184 que trata da desapropriação para fins de reforma agraria caso a terra em questão não esteja cumprindo sua função social será desapropriado.

Nos anos de 1990 pouco foi feito pela Reforma Agraria e a luta pela terra sofreu um retrocesso já esperado o governo Collor uma vez que o governo era neoliberal e a Reforma Agraria não era uma prioridade justificando porque esta década foi marcada por muitos conflitos agrários.

O governo de FHC é marcado pela implantação do projeto neoliberal no campo brasileiro, onde houve a criminalização dos movimentos sociais do campo e a criação da reforma agrária de mercado que entre os objetivos propõe:

i) manter e proteger o latifúndio; ii) estimular a produção agroexportadora; iii) desmobilizar, despolitizar e destruir os movimentos sociais que reivindicam a reforma agrária redistributiva; iv) criar um novo marco jurídico-institucional onde se possam implementar os projetos e programas de "desenvolvimento rural" [...]; v) reduzir as históricas lutas das populações camponesas à nova figura da "agricultura familiar", porque desta forma se individualiza e direciona a questão agrária para o âmbito doméstico. Para que reforma agrária - redistributiva - se o problema não é social e sim familiar? (CABRAL, 2014, p. 118)

O intuito era diminuir as pressões provocadas pelas ocupações de terra com a instituição de programas e de financiamento para compra de terras buscando assim desarticular e enfraquecer os movimentos sociais através da Reforma Agraria de mercado.

Ainda teve-se avanço e retrocessos ao longo dos mandatos de Lula onde os movimentos sociais tiveram o apoio do governo entre eles o MST onde participaram da elaboração do segundo Plano Nacional de Reforma Agrária (II PNRA) como finalidade, "além de garantir o acesso 
à terra, implementar ações que conduzissem as famílias a geração de renda, e também dar acesso a essas famílias a direitos fundamentais como: saúde, educação, saneamento, energia elétrica" (BRASIL, II PNRA, 2003)

Assim como o I PNRA nos governos anteriores, o II PNRA também foi pouco implementado ao longo dos oito anos de governo Lula. As metas do II PNRA não foram cumpridas, pois segundo o governo a prioridade eram os assentamentos.

Sabe- se que o capitalismo se expande a partir da renda territorial onde a terra é comprada, explorada e vendida objetivando sempre o lucro, base do capitalismo explicando assim os conflitos agrários uma vez que os grandes latifundiários objetivam o lucro sem a preocupação com as questões sociais e em contrapartida os camponeses buscam suas melhorias e de suas famílias, as lutas pela terra e pela reforma agrária são lutas contra o capital (MARTINS, 1995, p. 177).

\section{A guisa de conclusão}

A Amazônia no Brasil representa 61\% do território Nacional onde a maior parte dela é composta de terras indígenas e unidades de conservação ambiental do país. Temos visto ao longo dos anos o aceleramento do desmatamento, assoreamento dos rios, expropriação de terras, chacinas e genocídios de indígenas que ocorrem principalmente pela expansão do agronegócio.

Ao longo desse estudo percebemos uma Amazônia tanto em seus aspectos físicos, sociais e econômicos um espaço de diversidade ímpar disputada entre os povos nativos e aqueles que pretendem reeditar este espaço como fornecedor de matéria prima através de uma legislação ambiental que retoma uma série de iniciativas para flexibilizar a legislação ambiental que beneficiam as grandes empresas que atuam na Amazônia. São políticas de desmonte na legislação ambiental que iniciam desde o período colonial e mais recentemente ganha força dentro do atual governo que vem desestruturando muitas funções do Ministério do meio ambiente desarticulando políticas e temas recorrentes. 
A negação de direitos fundamentais sustentada por intermináveis e até questionáveis revisões das leis ambientais, agrarias, territoriais e sociais com decisões políticas retrocessivas e contraria a minorias e ao povo rural menos favorecido consiste em expediente de privilégios de interesse econômico pelos setores privados aumentando a desigualdade social espacial deteriorando o ambiente e as relações humanas dentro do espaço Amazônico.

\section{Referências}

COSTA; BRASILEIRO, Tania S. A. Cairé: cultura amazônica reinventada pelo marcado para a mídia. In: BURGEILE, Odete; BUENO, José Lucas Pedreira; PACÍFICO, Juracy Machado. Olhares da Mídia na Amazônia: movimentos e manifestações. Porto Velho: EDUFRO, 2016.

COLARES, Anselmo Alencar; COLARES, Maria Lília Imbiriba Sousa (Orgs). Educação e realidade amazônica. Uberlândia: Navegando Publicações, 2016. Disponível em: https://docs.wixstatic.com/ugd/ 35e7c6_877db987057646b79c466a958ea288e1.pdf >. Acesso: 28 julho de 2020. BRASIL. Decreto no 91.766, de 10 de Outubro de 1985. Aprova o Plano Nacional de Reforma Agrária - PNRA. Disponível em:< www.mda.gov.br/arquivos/I-PNRA.pdf>. Acesso em: 28 de julho de 2020.

- Ministério do Desenvolvimento Agrário. II Plano Nacional de Reforma Agrária: Paz Produção e Qualidade de Vida no Meio Rural. Agosto de 2003. Disponível em: Acesso em: 28 julho. 2020.

CABRAL, José Pedro Cabrera. Esquerda Progressista Uruguaia e a Reforma Agrária de Mercado: 2004-2011. In: OLIVEIRA, Ariovaldo Umbelino de; et al. (orgs) Território em Conflito, Terra e Poder . Goiânia: Kelps, p. 105-169, 2014 MARTINS, José de Souza.Os camponeses e a política no Brasil. $5^{a}$ ed. Petrópolis: Vozes, 1995.

LOUREIRO, J. de J.P. Cultura Amazônica: Uma poética do Imaginário. São Paulo: Escrituras, 473 p. 2001.

MAUÉS, R.H. Uma outra "invenção" da Amazônia: Religiões, Histórias, Identidades. Belém: Cejup, 283, p. 1999. 
OLIVEIRA, Ariovaldo Umbelino de. A longa marcha do campesinato brasileiro: movimentos sociais, conflitos e Reforma Agrária. Estudos Avançados. 2001, v.15, n.43, p. 185-206. Disponível em: . Acesso em: 24 dez. 2015.

RATZEL, Friedrich. Geografia do homem (Antropogeografia). In: MORAES, Antonio Carlos Robert de (Org.). Ratzel. São Paulo: Ática, 1990. p. 33-107.

SANTOS, Milton. A urbanização brasileira. $5^{a}$ edição. São Paulo: EDUSP, coleção "Milton Santos - 6", 2009.

STEDILE, João Pedro (org). A questão agrária no Brasil: O debate na esquerda - 1960-1980. 2. ed. São Paulo: Expressão Popular, 2012.

. João Pedro. O MST e a luta pela terra. In: Teoria e Debate. n. 24, 1994. p. 51-53. 